\title{
Kuhn e a Racionalidade da Escolha Científica
}

\author{
Eros Moreira de Carvalho
}

\begin{abstract}
In this paper, I try to articulate and clarify the role of the epistemic authority of experts in Kuhn's explanation for the transition process between rival paradigms in the scientific revolutionary period. If science progresses, that process should contribute to the attainment of the cognitive aim of science, namely, the articulation of paradigms increasingly successful at the resolution of problems. It is hard to see that process as rational and as attaining the cognitive aim of science without the consideration of epistemic authority. The mistake of Kuhn was to emphasize and clarify insufficiently the role of the epistemic authority of experts; his critics failed for ignoring it altogether.
\end{abstract}

Keywords: Thomas Kuhn; scientific rationality; epistemic authority; theory choice; scientific revolution.

\section{As acusações de irracionalismo e relativismo}

Ao descrever a transição entre paradigmas, ${ }^{1}$ Kuhn usou algumas expressões que posteriormente lhe renderam a acusação de relativismo e irracionalismo. Por exemplo, ele afirma que "uma decisão deste tipo (a adoção ou escolha de um novo paradigma) pode ser feita apenas com base na fé" ${ }^{2}$ (Kuhn 2012, p.157), o que pode sugerir que ela seria irracional, especialmente se atribuímos ao empreendimento científico uma finalidade epistêmica. Em relação à motivação individual para esta adoção ou escolha, Kuhn afirma que "a importância de considerações estéticas pode ser decisiva às vezes" (2012, p.155). Assim, elementos subjetivos parecem intervir na transição entre paradigmas. Em outras passagens, Kuhn sugere que a mudança de paradigmas não passa pela esfera do convencimento, mas da conversão. Ele diz: "A transferência de fidelidade de paradigma para paradigma é uma experiência de conversão que não pode ser forçada". Além disso, "a competição entre paradigmas não é o tipo de batalha que pode ser resolvida por provas" (2012, p.147) e mais adiante, "a transição entre paradigmas em competição não pode ser feita por um passo de cada vez, forçada pela lógica e pela experiência neutra" (2012, p.149). Por fim, como a transição entre paradigmas deve ser compreendida em ternos da experiência de conversão, devemos nos perguntar "como a conversão é induzida e resistida" (2012, p.151). E a resposta deverá apelar não a provas, mas a "técnicas de persuasão" (2012, p.151). Assim soltas e fora de contexto, essas afirmações dão a impressão de que a transição entre paradigmas é operada por decisões irracionais e causalmente motivadas por Principia 17(3): 439-458 (2013).

Published by NEL — Epistemology and Logic Research Group, Federal University of Santa Catarina (UFSC), Brazil. 
fatores subjetivos e emotivos. Se for assim, então é mesmo difícil escapar da conclusão relativista de que as crenças dos cientistas estavam tão justificadas antes da transição quanto estão mais tarde as suas novas crenças após a transição.

Não é difícil encontrar, na literatura subsequente à publicação de $S S R$, acusações de irracionalismo e relativismo. Já em 1964, Shapere escreve:

\begin{abstract}
"Kuhn está bem ciente do relativismo implicado pela sua posição... Kuhn já nos disse que a decisão de um grupo científico de adotar um novo paradigma não é baseado em boas razões... enquanto o livro de Kuhn chama a atenção para muitas confusões que foram feitas em relação às (boas) razões para a mudança científica, ele falha em iluminar estas razões, e mesmo obscurece a existência destas razões" (Shapere p.392-93).
\end{abstract}

No início da década de 80, tanto Israel Scheffler (1982, p.78-89) quanto Harvey Siegel (1980, p.211) questionaram se Kuhn não teria errado o alvo das suas considerações sobre a transição entre paradigmas. Elas não visariam o contexto de justificação desta transição, quanto muito, o contexto de descoberta da mesma, isto é, Kuhn estaria fornecendo não mais que uma explicação causal desta transição. Se fosse esse o caso, Kuhn poderia ser salvo das acusações de relativismo e irracionalismo, mas o preço seria a irrelevância do seu trabalho para as questões normativas que interessam ao filósofo da ciência. Assim, a posição de Kuhn precisa não só se esquivar do relativismo e do irracionalismo, mas também responder positivamente à questão normativa: a mudança de paradigma é um processo racional?

Em relação aos trechos da SSR citados acima, já no Posfácio, em 1969, Kuhn reclama que "apenas os filósofos interpretaram muito mal a intenção destas partes do meu argumento" (Kuhn 2012, p.197). Pouco tempo depois, em "Reflexões sobre os meus críticos", parece reconhecer parte da culpa pela má interpretação do seu trabalho quando proclama a pretensão de "eliminar os mal-entendidos pelos quais meu próprio passado retórico é, sem dúvida, parcialmente responsável” (Kuhn 1970, p.320). Mas, logo em seguida, atenua este reconhecimento quando insiste na acusação: "os tipos de mal-entendidos que acabo de esboçar são expressos apenas por filósofos, grupo já familiarizado com os pontos a que viso" (1970, p.322). Kuhn retoma o tema na palestra "Objetividade, juízo de valor e escolha de teoria", ministrada em 1973, e aí novamente larga a queixa: "diversos filósofos reagiram a essas observações de uma forma que ainda me surpreende. Disseram que minhas concepções fazem da escolha de teorias 'uma questão de psicologia de massas"' (Kuhn 1973, p.340). Por fim, quando Kuhn volta ao assunto em 1983, no artigo "Racionalidade e escolha de teorias", ele abre uma exceção para Hempel, mas arremata mais uma vez a sua insatisfação com a pouca caridade interpretativa que lhe fora dispensada pelos filósofos: "mais do que outros filósofos da sua linhagem, Hempel examinou minhas opiniões nessa área (escolha de teorias) com cuidado e simpatia. Ele não é

Principia 17(3): 439-458 (2013). 
um dos que supõem que proclamo a irracionalidade da escolha de teorias" (Kuhn 1983, p.256). Faço esse apanhado apenas para insinuar a convicção de Kuhn de que a sua posição em relação à questão da escolha de teorias já estava, nos seus pontos principais, bem estabelecida em 1962, sem querer com isso negar a contribuição bastante elucidativa dos textos subsequentes.

Defenderei que a posição de Kuhn sobre a questão da racionalidade da escolha entre paradigmas ou teorias rivais encontra-se, de fato, relativamente bem articulada nas duas últimas seções da $S S R$. Na última seção, Kuhn assinala a importância de se considerar a autoridade epistêmica dos membros da comunidade científica na explicação da transição entre paradigmas como um processo racional. Porém, como ele mesmo assinala na Introdução, sua explicação foi apenas esboçada:

\begin{abstract}
A Seção XIII perguntará como o desenvolvimento através de revoluções pode ser compatível com o caráter aparentemente único do progresso científico. Para esta questão, entretanto, este ensaio não fornecerá mais do que os contornos principais de uma resposta, uma que depende das características da comunidade científica que requer muita exploração e estudo adicionais. (Kuhn 2012, p.8)
\end{abstract}

Neste artigo, pretendo dar mais conteúdo e precisão à resposta kuhniana.

\title{
2. A escolha não é algorítmica
}

A acusação de irracionalismo não pode se seguir apenas da afirmação de Kuhn de que a escolha de uma teoria não pode ser resolvida ou decidida por meio de provas. Como ele explicita no Posfácio, afirmações neste sentido visavam apenas indicar que os debates em torno da escolha de teorias não poderiam ser colocados numa forma que se assemelhasse à prova matemática ou lógica (2012, p.198). Em outras palavras, estes debates não podem ser traduzidos em uma dedução, ainda que complexa. A evidência disponível aos cientistas não os constrange à aceitação de uma única teoria. E é claro que, mesmo que não haja regras dedutivas para determinar uma teoria face a evidência, o irracionalismo não se segue daí se temos ao menos razões não-dedutivas ou regras indutivas para selecionar uma teoria face a evidência. A adoção de razões ou regras falíveis pela comunidade científica para a escolha entre teorias rivais não pode sensatamente ser tomada como um sinal de irracionalidade. Kuhn, como logo veremos, não nega que haja essas regras ou boas razões para a escolha de uma teoria. Assim, não é por isso que Kuhn seria irracionalista. Porém, Kuhn nega que estas regras falíveis determinem unicamente a escolha de uma teoria, que o comprometimento dos cientistas com estas regras os comprometa, ainda que falivelmente, com a escolha de uma única teoria. No Posfácio, ele diz: "não há 
nenhum algorítimo para a escolha de teoria, nenhum procedimento de decisão sistemático que, propriamente aplicado, deve levar cada indivíduo no grupo à mesma decisão" (2012, p.198). Neste sentido, Kuhn nega a exequibilidade das teorias da confirmação. Neste ponto, o acusador de irracionalismo pode insistir que a recusa de Kuhn em tomar as regras falíveis como suficientes para a escolha de uma única teoria o compromete com o irracionalismo. Vejamos como esta acusação pode ser desenvolvida.

\section{As boas razões e a acusação irracionalista}

Na seção XII da $S S R$, Kuhn arrola 4 tipos de razões que geralmente são dadas pelos cientistas para preferir uma teoria nova no contexto de debate entre paradigmas. São elas: (1) a resolução da anomalia que levou a teoria antiga à crise (2012, p.151), (2) precisão quantitativa das previsões superior a da teoria antiga (2012, p.153), (3) a previsão de fenômenos inesperados (2012, p.153) e, por fim, (4) a percepção de que a teoria é mais simples ou apropriada (2012, p.154). Kuhn explicitamente diz que as razões (1)-(3) são mais significativas e decisivas que a razão de tipo (4), embora esta última também tenha um papel importante a cumprir e o indicaremos logo mais. As razões dos tipos (1)-(3) são indicadores da habilidade comparada da teoria ou paradigma de resolver problemas. A razão do tipo (4) é qualificada por Kuhn como estética, subjetiva e idiossincrática (2012, p.155). Embora essas razões isolada ou combinadamente possam persuadir muitos cientistas a adotar a nova teoria, nenhuma delas, em separado ou em conjunto, é suficiente para obrigar e constranger racionalmente o cientista a escolher uma única teoria. Isso significa não só que estas razões não são conclusivas, como já havíamos indicado, mas também que, durante o debate, está em questão o quão boas são estas razões. É importante deixar claro o objetivo da comparação entre teorias rivais, isto é, a qualidade das teorias com relação a qual se espera mostrar, no contexto de debate científico, que uma é melhor do que a outra. O que está em questão, diz Kuhn, é a capacidade não só presente, mas futura da teoria de solucionar problemas (2012, p.156). As razões (1)-(3) atestam diretamente a capacidade presente da teoria em solucionar problemas, mas não a futura. Não são, assim, razões conclusivas para este fim, nem há completo consenso sobre quão boas elas são para este fim.

A acusação de irracionalismo pode explorar este último ponto. Se não há consenso sobre quão boas as razões (1)-(4) são para aferir não-conclusivamente a capacidade futura das teorias rivais de resolver problemas, então alguns cientistas podem, por exemplo, achar as razões (1) e (2) boas o bastante para escolher uma teoria enquanto outros cientistas fiéis a um paradigma alternativo consideram as mesmas razões boas o bastante para não escolher esta teoria, mas a sua rival. Parece então que

Principia 17(3): 439-458 (2013). 
o julgamento de quão boas essas razões são é completamente arbitrário e, portanto, o processo de escolha entre teorias é irracional. Essa conclusão pode ser agravada se levamos em conta as considerações de Kuhn a respeito da incomensurabilidade metodológica. ${ }^{3}$ Paradigmas determinam a lista de problemas que devem merecer a atenção do cientista (2012, p.147). Isso significa que um paradigma emergente, embora geralmente surja para resolver uma anomalia do paradigma antecessor, não tem necessariamente de resolver todas as suas anomalias, pois pode mesmo desconsiderar algumas delas como problemas genuínos. Cientistas de diferentes paradigmas podem então nem mesmo concordar que uma nova teoria resolve as anomalias da antiga teoria. Paradigmas também determinam o que, nos laboratórios de pesquisa, o cientista está apto a ver e observar diretamente (2012, p.149), o que é um efeito da incomensurabilidade semântica. E assim cientistas de diferentes paradigmas podem também discordar que uma nova teoria realiza uma predição inesperada, pois o cientista fiel ao antigo paradigma não consegue ver o fato inesperado que o defensor do novo paradigma diz observar e ser uma decorrência da sua teoria. Cientistas de diferentes paradigmas podem não só discordar quanto às razões disponíveis para inferir qual teoria é mais capaz de resolver problemas, mas também quanto a quão boas são estas razões.

No Posfácio e nos artigos posteriores, ao invés de falar em razões inconclusivas ou regras falíveis, Kuhn opta por falar em valores e critérios cognitivos empregados pelos cientistas na escolha entre teorias rivais. Estes valores e critérios são compartilhados pelos cientistas (2012, p.204; 1973, p.341). A incomensurabilidade, é importante enfatizar, jamais é global. ${ }^{4}$ Porém, a variação efetiva entre os cientistas na escolha de teorias rivais pode ser explicada pela variação individual na aplicação destes valores e critérios e pela variação individual no peso relativo atribuído a cada um desses critérios. O principal valor cognitivo que se espera encontrar em uma teoria é ainda a sua capacidade de resolver problemas (2012, p.204; 1983, p.257). Para averiguar se a teoria tem esta capacidade, os cientistas se apoiam em uma série de critérios. No Posfácio, são: acurácia da predição, equilíbrio entre problemas esotéricos e de ciência normal, número de diferentes problemas resolvidos, simplicidade, escopo e compatibilidade com outras especialidades (2012, p.204). Esses critérios são muito próximos das razões (1)-(4) presentes no capítulo XII e não mudam muito nos artigos posteriores. As considerações gerais de Kuhn também permanecem as mesmas. O fim do debate é decidir que teoria tem maior capacidade presente e futura de resolver problemas. Os critérios arrolados servem como indicadores desta capacidade. Alguns critérios, como a acurácia da predição, são mais inequívocos na sua aplicação. Outros, como a simplicidade, são mais suscetíveis às idiossincrasias (1973, p.343). Essa distinção entre critérios mais e menos inequívocos ou objetivos já tinha sido feita entre as razões (1)-(4). A vantagem é deixar mais claro que a incomensurabilidade metodológica não é total, pois a comunidade 
científica como um todo compartilha esses valores e critérios cognitivos. Ao mesmo tempo, a variação na aplicação dos critérios explicita o desacordo entre cientistas com respeito às razões disponíveis para preferir uma ou outra teoria, e a variação no peso relativo atribuído a cada um desses critérios explicita o desacordo entre cientistas com respeito ao quão boas eles consideram as razões que lhe estão disponíveis. Há ganho em clareza, mas não há novidade substancial.

A despeito da limitação da incomensurabilidade, o acusador de irracionalismo ainda se incomodará com o fato de que há variação em demasia na aplicação dos critérios e nos pesos relativos atribuídos a cada um. Além disso, o próprio Kuhn reconhece que alguns desses critérios são mais equívocos na sua aplicação e suscetíveis a idiossincrasias. Se isto não torna as escolhas individuais dos cientistas caprichosas e, portanto, cognitivamente irracionais, o que mais as tornaria?

\section{O papel dos fatores subjetivos}

Mesmo que a racionalidade da escolha individual seja comprometida pela atuação de fatores idiossincráticos, o processo de transição entre paradigmas pode ele mesmo não ser irracional. Essa é uma ideia que pode ser desenvolvida para afastar a acusação de irracionalismo, pelo menos o irracionalismo do processo de transição. $\mathrm{O}$ ponto central a ser defendido é que o processo, a despeito das escolhas individuais irracionais, ou até mesmo em virtude delas, realiza, ao longo do tempo, a finalidade de selecionar coletivamente a teoria de melhor capacidade de resolução de problemas. Dissemos que Kuhn reserva um papel importante na sua explicação da transição entre paradigmas para os fatores idiossincráticos que acabam motivando as escolhas individuais dos cientistas. É hora e explicar este papel e ver como Kuhn articula a racionalidade do processo de transição coletiva entre paradigmas.

A explicação do papel dos fatores idiossincráticos na transição entre paradigmas é bastante simples. Lembremos que o debate entre paradigmas diz respeito à determinação de qual paradigma é mais promissor na resolução de problemas. Mas se as únicas razões para preferir um paradigma a outro fossem as razões de tipo (1)-(3) ou os critérios cuja aplicação é menos equívoca, jamais haveria revoluções científicas ou transições entre paradigmas. O novo paradigma, logo quando aparece, ainda é muito pouco articulado e incapaz de resolver efetivamente muitos problemas. Em uma avaliação comparativa acerca da capacidade presente de resolver problemas, o paradigma novo majoritariamente será considerado inferior, ainda que o antigo paradigma já tenha acumulado persistentemente muitas anomalias e esteja em crise (2012, p.156). Ademais, não se pode excluir completamente a possibilidade de que a crise seja sanada com mais atividade de ciência normal, como já ocorreu em outras ocasiões. Dada a finalidade de encontrar paradigmas mais promissores, parece

Principia 17(3): 439-458 (2013). 
então cognitivamente saudável, ao menos na perspectiva coletiva, que alguns indivíduos escolham o novo paradigma em seu estágio inicial para então desenvolvê-lo e articulá-lo até o ponto em que razões de tipo (1)-(3) possam ser dadas a seu favor. Para que a escolha prematura ocorra, é preciso então que as razões idiossincráticas sobrepujem, para alguns cientistas, as razões de tipo (1)-(3) no seu julgamento do quão promissor é o novo paradigma. Isto de fato acontece. Mas também não é razão para alarme, como se toda a comunidade fosse, de hora para outra, mudar de paradigma por razões idiossincráticas. Se esta possibilidade fosse recorrente, a atividade científica também cessaria, pois minaria a ciência normal. No entanto, como assinala Kuhn, "poucos sujeitos desertam uma tradição por estas razões apenas" (2012, p.157). Assim, por um lado, para evitar o excesso de parcimônia e impedir as revoluções científicas, é necessário que alguns cientistas adotem o novo paradigma sobretudo por razões idiossincráticas; por outro, para evitar a corrupção da ciência normal, é também fundamental que poucos o façam. Vê se aqui, como Kuhn enfatiza várias vezes, que a variabilidade individual é proveitosa para que comunidade científica como um todo realize seus fins cognitivos.

Por fim, se o novo paradigma tiver de triunfar e conquistar a fidelidade da comunidade como um todo, ele o fará pelos critérios mais objetivos, aqueles cuja aplicação é menos equívoca (SSR, p.157). Só depois de bem articulado ele poderá conquistar a confiança da maioria dos cientistas pelas boas razões. "Ao invés de uma única conversão de grupo, o que ocorre é uma mudança crescente na distribuição da fidelidade profissional" (2012, p.157). A transição entre paradigmas é um longo processo cujo resultado pode ser considerado racional pelo fato de que a adesão ao paradigma vencedor se dará majoritariamente por boas razões ou pela satisfação dos critérios mais objetivos. Para Kuhn, parece importar menos a irracionalidade pontual de algumas decisões individuais e mais o resultado final do debate entre paradigmas. No capítulo XII, ele já assinalava: "nos preocuparemos menos então com os argumentos que de fato convertem um ou outro indivíduo, mas com o tipo de comunidade que cedo ou tarde se reforma como um único grupo" (2012, p.152). No Posfácio, fica ainda mais visível a mudança de foco no indivíduo para a comunidade:

\footnotetext{
é a comunidade de especialistas, ao invés dos membros individuais, que faz a decisão efetiva. Para entender a maneira como a ciência se desenvolve, não é necessário desvelar os detalhes da biografia e personalidade que leva cada indivíduo a uma escolha particular, embora este tópico seja fascinante. O que se deve entender, contudo, é a maneira pela qual um conjunto particular de valores compartilhados interage com as experiências particulares compartilhadas por uma comunidade de especialistas para assegurar que a maioria dos membros do grupo acharão por fim um conjunto de argumentos ao invés de outro decisivo. (SSR, p.199)
}

Uma comunidade científica virtuosa na realização do fim de adotar paradigmas

Principia 17(3): 439-458 (2013). 
cada vez mais promissores na resolução de problemas é a que distribui entre os seus membros o risco do que deve ser aceito, permitindo o surgimento de novos paradigmas sem ameaçar a existência da ciência normal. Lembremos também que a rejeição de um paradigma em crise não ocorrerá até que haja outra alternativa em vista. Esta distribuição equilibrada é obtida pelo compartilhamento de valores e critérios cognitivos cuja aplicação está sujeita à variabilidade individual. Contra a acusação de irracionalismo, Kuhn então sustenta que a irracionalidade pontual de algumas decisões individuais não contamina a racionalidade do processo de transição entre paradigmas. Na verdade, ela é mesmo necessária para que a comunidade satisfaça o seu fim cognitivo.

\section{A acusação persistente de irracionalidade}

Algumas questões ainda carecem de resposta. De fato a adoção de um novo paradigma no seu estágio mais inicial é irracional? Mesmo no estágio em que o novo paradigma já se encontra amadurecido e a sua adoção se dê majoritariamente em virtude da satisfação dos critérios mais objetivos, podemos dizer que a comunidade garantidamente está adotando o paradigma mais promissor? O processo de transição realmente atende o fim a que se propõe?

Quanto à primeira questão, Kuhn parece de fato sustentar que estas decisões iniciais são irracionais. "O sujeito que adota um novo paradigma no estágio inicial deve frequentemente fazê-lo desafiando a evidência fornecida pela solução de problemas. Ele deve ter fé em que o novo paradigma será bem sucedido" (2012, p.156-57). E logo em seguida ele diz que a base para esta fé, a apreciação estética, não precisa ser nem racional, nem correta. Mas como acabamos de ver, isso não afeta a racionalidade do processo de transição entre paradigmas. Na verdade, a adesão irracional de alguns poucos ao novo paradigma é mesmo necessária.

Retomemos agora a situação em que o novo paradigma já se encontra relativamente articulado e desenvolvido. Neste estágio, ele satisfaz os critérios mais objetivos de escolha de teorias, como acurácia das predições, realização de predições novas, resolução de um grande número de problemas etc. Mas também não há como negar que o antigo paradigma satisfaça estes critérios. Os debates se intensificam, fidelidades são trocadas. Como uma questão de fato, cedo ou tarde, a transição entre paradigmas se completará ou o paradigma novo será descartado como infrutífero. Porém, a pergunta é se, neste estágio, os critérios mais objetivos são suficientes para constranger os cientistas a adotar um ou outro paradigma. Lembremos que, para Kuhn, por mais objetivos que os critérios sejam, eles não deixam de ter algum grau de equivocação na sua aplicação. A resposta, então, à pergunta é negativa. Nenhum desses critérios ou argumentos mais objetivos apresentados durante o debate entre

Principia 17(3): 439-458 (2013). 
paradigmas é, para usar a expressão de Kuhn, "individualmente decisivo" (2012, p.157). As variações individuais, neste estágio, podem ser muito pequenas, seja na constatação de que a teoria satisfaz os critérios compartilhados, seja nos pesos relativos atribuídos aos critérios. Ainda assim, mesmo que alguma unanimidade seja obtida, ela não poderá ser explicada pela aplicação automática de um conjunto de critérios objetivos. A contribuição individual, por menor que seja, neste estágio, não pode ser eliminada do processo. Mas é justamente nesta fenda de subjetividade que o crítico de Kuhn apoia a sua persistente acusação de irracionalidade. Se as decisões individuais dos cientistas não são constrangidas por razões completamente objetivas, a unanimidade obtida, quando obtida, não repousará completamente sobre razões objetivas. Isto, dirá o crítico, compromete a objetividade do julgamento comparativo de que o paradigma então adotado é mais promissor na resolução de problemas do que a alternativa descartada. Não está em questão aqui a objetividade do julgamento de que, neste estágio, ambos os paradigmas são promissores em alguma medida na resolução de problemas. O crítico aceita o ponto de Kuhn de que o debate, neste estágio, está sendo pautado por razões e critérios substancialmente objetivos. Seu ponto é que a intromissão de elementos subjetivos compromete a objetividade do julgamento comparativo. E se compromete, então a transição para o novo paradigma ou mesmo a sua rejeição parecerá arbitrária, ou pelo menos relativamente arbitrária. Deste modo, não parece que Kuhn possa se abster de explicar a racionalidade da decisão individual, mesmo nos casos mais maduros em que os debates entre paradigmas estão sendo travados a partir de razões ou critérios mais objetivos.

\section{A escolha de teorias e o problema da indução}

Para ver as decisões dos cientistas como racionais, precisamos lançar mais luz sobre o que ele eles estão fazendo. O debate entre paradigmas é uma disputa sobre "qual paradigma deve no futuro guiar a pesquisa acerca de problemas muitos dos quais nenhum dos competidores pode ainda alegar resolvê-los completamente" (2012, p.156). Como já tinha sido indicado, o problema é estimar qual paradigma é mais promissor, qual paradigma se mostrará melhor sucedido na solução de problemas. No debate entre paradigmas, os cientistas estão assim disputando um julgamento de plausibilidade, um juízo indutivo. As razões de tipo (1)-(4) ou a satisfação dos critérios mencionados no Posfácio e a consideração de quão boas são estas razões ou o peso relativo atribuído a cada um destes critérios constituem a base indutiva para tal julgamento. Cientistas divergem em seus julgamentos comparativos e indutivos na justa medida em que varia a sua base indutiva. A evidência acumulada por cada cientista e o seu conhecimento de fundo não podem ser aqui negligenciados. Em grande medida, eles são responsáveis pela variação da base indutiva. Em função 
desta variação, cientistas divergirão na aplicação dos critérios aos paradigmas concorrentes ou na atribuição dos pesos relativos aos critérios aplicados. O resultado é um julgamento comparativo de índole indutiva possivelmente divergente quanto a qual paradigma será mais promissor na resolução de problemas.

Poderíamos ser tentados aqui pela ideia de que o somatório da evidência acumulada por cada cientista, isto é, aquilo que podemos chamar de evidência total, determina unicamente, ainda que falivelmente, a escolha pelo paradigma mais promissor. E conforme os cientistas individualmente compartilhassem mais e mais da evidência coletiva acumulada, suas escolhas, se feitas de acordo com a evidência, tenderiam a convergir. Esta ideia pode ser entendida de duas formas. Podemos pensá-la como a busca de cânones objetivos relacionando a evidência e a teoria, cânones que devem constranger externa e racionalmente a escolha individual do cientista. A objetividade em questão é em princípio completamente externa à prática indutiva científica, ela deve poder ser caracterizada de modo algorítmico. Deve ser possível provar que tais cânones relacionando evidência e teoria garantem que a teoria selecionada em comparação com outras será provavelmente mais bem sucedida, na acepção objetiva de probabilidade. Mas a prova externa de confiabilidade para os cânones indutivos é uma que ainda esperamos ser dada. ${ }^{5}$ De qualquer modo, é importante que fique claro: se este é o tipo de objetividade que está em questão, então, na perspectiva do acusador de irracionalismo, a escolha individual do cientista poderá ser irracional ou pelo menos afastar-se do ideal de racionalidade por duas razões: conforme ele escolha sem contemplar a evidência coletivamente acumulada e conforme ele divirja da decisão sancionada pelo cânone mesmo contemplando a evidência coletivamente acumulada. Assim, os cientistas que escolhem prematuramente um paradigma com base nas razões ou critérios mais subjetivos estariam fazendo uma escolha individual irracional. De modo semelhante, os cientistas que, no estágio mais maduro do debate, emitem um juízo comparativo diferente daquele sancionado pelos cânones, fazem uma escolha individual irracional.

A objetividade dos cânones indutivos herdados não precisa estar pautada numa prova externa de confiabilidade, ela pode estar assentada no reconhecimento pelos membros da comunidade científica de que estes cânones codificam os nossos melhores procedimentos inferenciais da prática científica. Trata-se de uma objetividade que não é externa à prática científica, mas interna e constituída por ela. Um exemplo de tentativa de codificação da prática indutiva seria a teoria da projetabilidade de Goodman. E uma regra canônica da prática científica atual, segundo esta teoria, seria a restrição da aplicação da indução por enumeração a bases indutivas descritas apenas com predicados projetáveis. Na teoria de Goodman, a distinção entre predicados projetáveis e não-projetáveis faz quase todo o trabalho de codificação da prática indutiva atual (Goodman 1983a, p.94). A objetividade portanto alcançada por esta codificação não é externa à prática indutiva. De qualquer modo, ainda

Principia 17(3): 439-458 (2013). 
temos cânones intersubjetivos que constrangem racionalmente as escolhas individuais. O crítico de Kuhn pode novamente levantar a sua insatisfação nos termos da teoria de Goodman. A escolha mais racional é aquela sancionada pelos cânones aplicado à base indutiva coletivamente acumulada e descrita apenas por predicados projetáveis. A escolha individual pode afastar-se deste ideal de racionalidade ou por desconsiderar a evidência total, ou, ainda que a considere, por preferir uma teoria que é menos projetável segundo os cânones indutivos. Não parece haver ainda espaço para a interferência dos fatores mais subjetivos na escolha individual sem que a sua racionalidade seja abalada. A prática indutiva coletiva herdada constrange o julgamento comparativo de qual teoria será mais bem sucedida diante da evidência coletivamente acumulada.

Embora a prática indutiva herdada constranja os julgamentos comparativos individuais dos cientistas, e é razoável que o faça, o que queremos saber é se ela deve constrangê-los em absoluto. A teoria da projetabilidade parece dar conta relativamente bem de explicar os julgamentos indutivos feitos justificadamente durante a ciência normal, por exemplo, aqueles julgamentos que incidirão sobre a escolha de qual hipótese auxiliar ou qual condição inicial deve ser responsabilizado por uma previsão mal sucedida. Mas o debate acerca da escolha entre teorias alternativas e rivais é um que se estabelece durante períodos de revolução científica. Neste caso, os efeitos da incomensurabilidade local não podem ser negligenciados. A evidência acumulada por cada cientista já não pode mais ser somada coerentemente. Cientistas já não concordam sobre a base empírica, sobre o que observam nas mesmas situações de observação e experimentação. Está em disputa boa parte do sistema mais básico de categorias, predicados projetáveis, tipos naturais, isto é, toda uma estrutura lexical a partir da qual a própria evidência acumulada será descrita e sobre a qual os cientistas farão projeções indutivas. Cientistas estão disputando qual sistema de predicados projetáveis será mais promissor na resolução de problemas. E embora os paradigmas em disputa tenham pontos de contato e não sejam globalmente incomensuráveis entre si, o compromisso com os predicados projetáveis comuns a ambos os paradigmas não determina indutivamente a escolha dos demais predicados que estão em conflito. E agora o nosso problema é explicar como esta escolha individual, dada a finalidade da comunidade científica de obter paradigmas cada vez mais promissores na resolução de problemas, pode ser vista como cognitivamente racional se ela não é constrangida nem mesmo pela prática indutiva herdada. Na verdade, está mesmo em disputa o estabelecimento de nova prática indutiva.

A relação sugerida acima entre o problema da racionalidade da escolha de teorias no contexto de revoluções científicas e o problema clássico da justificação da indução não é de modo algum estranha a Kuhn. Em uma passagem de $S S R$, ele diz: "se pudermos aprender a substituir a evolução-em-direção-ao-que-queremos-saber pela evolução-a-partir-do-que-sabemos, diversos problemas vexatórios podem desapare- 
cer no processo. Por exemplo, o problema da indução deve se encontrar em algum lugar deste labirinto" (Kuhn 2012, p.170). O problema da indução desaparecerá se entendermos a sua objetividade como interna à prática indutiva e se conseguirmos dar uma explicação satisfatória para as mudanças mais substanciais desta prática durante o processo de transição entre teorias rivais e parcialmente incomensuráveis, uma explicação que preserve a racionalidade epistêmica da prática indutiva resultante.

\section{Putnam e a racionalidade da escolha individual}

Em Razão, Verdade e História, comentando sobre a objetividade do juízo ético, Putnam diz:

A ideia de que em alguns assuntos, entre eles questões éticas, as considerações a ponderar são justamente tão complexas, e tão imprecisas, que não podemos esperar confiar em nada como uma prova científica ou definições científicas, tendo que confiar na percepção e no juízo é uma ideia antiga. É plausível que uma das mais elevadas manifestações de racionalidade devesse ser a capacidade para julgar com correção precisamente nesses casos em que não podemos esperar "provar" coisas de modo a satisfazer a maioria. Parece realmente estranho que o fato de algumas coisas deverem ser impossível de provar de modo a satisfazer toda a gente deva tornar-se num argumento em favor da irracionalidade das crenças acerca destas coisas. (Putnam 1992, p.224)

Esta consideração só não é, segundo Putnam, estendida à racionalidade científica em virtude do fetichismo com o método e a esperança de que pudéssemos estabelecer a objetividade dos cânones indutivos que relacionam teoria e evidência por meio de provas de confiabilidade externas à prática indutiva. Mesmo a aplicação do teorema de Bayes a esta questão esbarrou em sérias limitações. Para calcular a probabilidade de uma hipótese face à evidência com o auxílio do teorema, temos antes de alimentar a fórmula com a probabilidade subjetiva a priori da hipótese em questão. Mas é justamente a racionalidade deste julgamento de probabilidade que está em questão no contexto de debate entre hipóteses rivais. A racionalidade deste julgamento é que precisa ser explicada.

Mesmo que a tentativa de assentar completamente a racionalidade científica em uma objetividade externa à própria prática indutiva esbarre em sérias dificuldades, disto se segue que possamos ver as decisões individuais dos cientistas no contexto de debate entre teorias ou paradigmas rivais como similares às decisões individuais no debate de questões éticas? Antes disso, é pacífico, como Putnam afirma, que admitimos a racionalidade moral de decisões individuais no campo da ética sobre o que é certo e errado mesmo na ausência de uma prova externa da correção do nosso

Principia 17(3): 439-458 (2013). 
pensamento ético? Não seria o caso de concluirmos também pela irracionalidade das decisões éticas? Deixemos de lado as decisões éticas e vejamos o que Putnam diz em outro lugar sobre a racionalidade das decisões existenciais ou prudenciais.

Em "Sobre a racionalidade das preferências", Putnam critica o que parece ser uma consequência da teoria clássica da preferência racional, a saber, que "não é possível, para um ser perfeitamente racional, encarar certos bens como incomparáveis" (Putnam 2004, p.111). Se assumimos que deve haver sempre uma relação de preferência entre bens, então é irracional tomar certos bens como incomparáveis. Sempre que o sujeito não tiver ainda uma preferência entre $\mathrm{x}$ e $\mathrm{y}$, a única atitude racional que o sujeito pode ter em relação a estes bens é a de indiferença. E, sendo assim, tanto faz se lhe dermos x ou y. Mas é justamente esta consequência que, para Putnam, é inaceitável. Ele nos convida a supor o caso de Teresa, que hesita entre um modo de vida hedonista e um modo de vida asceta. Para ela, esses modos de vida são incomparáveis. Ou seja, não há como ela constranger a sua escolha por um ou outro a partir de outras preferências que ela já possui. Mas, pela teoria, a atitude de alegar incomparabilidade entre os modos de vida como distinta da atitude de declarar indiferença a eles é irracional. E, na verdade, se Teresa não prefere ainda nem o modo de vida hedonista, nem o modo de vista asceta, ela tem de aceitar que podemos escolher para ela um ou outro, por exemplo, lançando uma moeda (2004, p.112). O fato bruto acerca da vida que parece ser negligenciado pela teoria é que a escolha entre bens incomparáveis deve caber ao agente; o que o agente quer é escolher por sua própria vontade, após refletir e deliberar autonomamente, entre uma vida e outra. Mas, então, é preciso assumir que a relação de preferência entre um e outro modo de vida não é dada de antemão, mas será determinada pela escolha deliberada e autônoma do agente. Assim, a valorização da autonomia do agente é o que nos leva a tomar as suas escolhas existenciais como racionais, mesmo que ele não possa rastrear determinadamente estas escolhas em termos de outras preferências que ele já tinha. Na verdade, é justamente por não poder fazer este rastreio que a sua autonomia pode ser neste caso exercida.

Tomando de empréstimo a ideia de Putnam, resta saber agora se temos alguma razão para valorizar uma autonomia semelhante no âmbito das decisões científicas. Valorizamos a autonomia na escolha de decisões existenciais, pois reconhecemos que cada sujeito tem autoridade quase absoluta sobre a condução da sua vida. Se não nos víssemos com tal autoridade, não valorizaríamos, nem nos concederíamos a autonomia nas escolhas existenciais e prudenciais. Mas certamente nada está mais distante da verdade que reconheçamos cada sujeito como tendo autoridade quase absoluta na condução da sua vida cognitiva. E a razão substancial para tanto é que reconhecemos uma série de regras epistêmicas que devem ser obedecidas para a boa condução das mais diversas atividades intelectuais. Por exemplo, a exigência de não negligenciar a evidência contrária, a exigência de não realizar generalizações

Principia 17(3): 439-458 (2013). 
apressadas, a exigência de não aceitar o testemunho de pessoas sabidamente incompetentes, a exigência de deferir aos especialistas nos assuntos de sua competência etc. Não temos autonomia epistêmica para negligenciar o respeito a estas regras e ainda pleitear que nossas crenças sejam relevadas e consideradas pelos nossos parceiros intelectuais. Justamente porque nos assuntos cognitivos essa autonomia não é creditada ao grosso da humanidade, aqueles que se portarem como se a tivessem serão alijados da vida cognitiva comum.

Mas estas considerações não encerram a questão. A autonomia intelectual não é creditada ao grosso da humanidade pela razão óbvia de que a maioria das pessoas não são autoridades epistêmicas. O grosso da humanidade tem a sua vida cognitiva constrangida pela autoridade das regras epistêmicas herdadas, os cânones indutivos aí inclusos. Mas disso não se segue que a autonomia intelectual não seja creditada em algum grau aos especialistas. Na verdade, ela será creditada na justa medida em que os especialistas são autoridades epistêmicas. A própria existência de especialistas na composição do nosso tecido cognitivo nos força a reconhecê-los como tendo uma autoridade epistêmica que o grosso da humanidade não possui. Ainda assim, temos de perguntar: a autoridade epistêmica dos especialistas significa apenas que eles são mais peritos que o grosso da humanidade na aplicação das regras epistêmicas herdadas e dos cânones indutivos ou, mais do que isso, os especialistas têm alguma autonomia intelectual com relação às regras epistêmicas e, em especial, com relação aos cânones indutivos herdados?

\section{A autoridade epistêmica do especialista}

Se a objetividade dos cânones indutivos não é externa à própria prática indutiva, mas repousa no reconhecimento pelos membros da comunidade científica de que eles codificam os melhores procedimentos inferenciais da prática científica, então há um argumento simples para vermos a decisão individual do cientista no contexto de debate entre paradigmas como devendo ter autoridade epistêmica. Embora o acordo final entre os membros da comunidade científica confira uma autoridade epistêmica aos cânones e predicados acordados bastante superior àquela que tinham antes do veredito final, é difícil negar que eles não tivessem inicialmente alguma autoridade epistêmica, mesmo antes de serem compartilhados. O acordo entre pessoas epistemicamente negligentes sobre o que quer que seja não é revestido de autoridade epistêmica. O acordo só majora a autoridade epistêmica do que antes já tinha alguma. Assim, se reconhecemos que os cânones indutivos herdados têm autoridade epistêmica, temos de reconhecer que as decisões científicas passadas que o constituíram já tinham alguma autoridade epistêmica também. $\mathrm{O}$ acordo com respeito aos cânones indutivos reveste-se de grande autoridade epistêmica por ser o resultado

Principia 17(3): 439-458 (2013). 
do debate entre membros de uma comunidade científica. Em última instância, é sobre a autoridade intelectual dos especialistas que repousa a autoridade epistêmica dos cânones indutivos herdados e acordados e não o contrário. Sendo assim, temos de reconhecer que os especialistas têm alguma autonomia na decisão científica em relação aos cânones indutivos herdados.

Uma objeção ao argumento acima seria a de que a autoridade conferida aos cânones indutivos não se deve ao acordo entre especialistas, mas ao processo de debate por meio do qual tais especialistas entraram em acordo. É a estrutura do debate e os argumentos estabelecidos através dele que conferem autoridade epistêmica aos cânones assim acordados. Embora a diversidade de pontos de vista no debate majore o estatuto epistêmico dos acordos obtidos, o debate entre especialistas no período revolucionário tem feições muito especiais. Não se trata, na verdade, de um debate mediado exclusivamente por argumentos indutivos, pois, como acabamos de ver, parte dos cânones indutivos estão sob disputa. Não há critérios externos à prática indutiva para decidir a disputa. Nem a parcela do cânone indutivo compartilhada é suficiente para decidir sobre a parcela em litígio. Ambos os paradigmas em disputa pontuam igualmente bem, neste estágio do debate, segundo os critérios e razões mais objetivos. Neste sentido, é um diálogo de surdos, como, às vezes, coloca Kuhn (2012, p.109). Mas é um diálogo de surdos apenas no que concerne à possibilidade de decidir a disputa por meio de argumentos canônicos. Lembremos da passagem polêmica de Kuhn dizendo que a transição entre paradigmas não pode ser forçada por provas e que, para o cientista, ela lembra mais uma experiência de conversão. Disto não se segue que o debate seja infrutífero e não possa fomentar a mudança de posição. Como coloca Goodman, quando o que está em disputa é todo um sistema de categorias, isto é, todo um paradigma, "o que precisa ser mostrado não é a sua verdade, mas o que ele pode fazer. Falando grosseiramente, o que se pede nesses casos é muito menos argumentar do que vender" (Goodman 1983b, p.91). Kuhn também assinala que a relativa circularidade do debate neste estágio não é infrutífera, "o sujeito que coloca o paradigma como premissa ao argumentar em sua defesa pode contudo prover uma exibição clara de como será a prática científica para aqueles que adotam a nova visão da natureza" (2012, p.94). Essas exibições não são provas, nem são evidência indutiva determinante do sucesso futuro do paradigma em resolver problemas. No entanto, elas mediam para o oponente alguma medida de compreensão do paradigma rival. Este tipo de debate é o análogo à deliberação individual do sujeito que decide por um bem ou opção prudencial. A deliberação individual é necessária para que o sujeito exerça a sua autonomia e constitua pela sua decisão qual dos bens, até então incomparáveis, é melhor do que o outro. A deliberação não é supérflua, sem ela o indivíduo não teria feito mais do que uma decisão caprichosa aos nossos olhos e aos seus próprios. De modo semelhante, o debate entre paradigmas rivais é necessário para que o cientista exerça a sua autonomia 
epistêmica em relação aos cânones indutivos herdados. Sem uma mínima compreensão do paradigma alternativo, não há como enxergar a autoridade epistêmica do seu juízo comparativo. Assim, se a autoridade epistêmica do paradigma vencedor em relação ao seu rival não pode se dever exclusivamente às provas, dedutivas ou indutivas, pois não há tais provas que o favoreçam unicamente, nem ao mero acordo sem maiores qualificações, então ela tem de se dever em grande medida à autoridade epistêmica dos especialistas. E esta última precisa ser entendida no sentido mais forte de que os especialistas têm alguma autonomia epistêmica em relação aos cânones indutivos herdados. $\mathrm{O}$ acordo estabelecido em torno de um paradigma e as razões objetivas que ele tem em seu favor sem dúvida contribuem para a autoridade epistêmica atribuída ao paradigma vencedor, mas esses dois elementos não são ainda suficientes para explicar a racionalidade epistêmica do juízo comparativo resultante do término do debate. A racionalidade deste juízo repousa em alguma medida sobre a autoridade epistêmica dos especialistas. $\mathrm{O}$ acordo então obtido, agora qualificado, acordo entre especialistas, é um que realmente majora a autoridade epistêmica do paradigma vencedor.

A autonomia epistêmica reconhecida e concedida ao especialista não é total, mas é suficiente para explicar como racionais as decisões variadas dos cientistas, no contexto de debate entre paradigmas, quanto a qual deles será mais promissor. Pode-se dizer que a escolha individual por um paradigma, por um conjunto novo de léxicos e predicados projetáveis, tem autoridade epistêmica prima facie. Isto significa que ela merce crédito e atenção entre os membros da comunidade científica. Os demais membros da comunidade devem em alguma medida considerar se o paradigma defendido pelo seu par intelectual e as projeções que ele acarreta são promissores. Ele deve tentar compreender o que o paradigma rival pode fazer. Contudo, a autoridade vinculada ao julgamento individual do cientista é também anulável. Ela poderá ser derrotada no debate, ela pode falhar substancialmente no equilíbrio reflexivo entre os membros da comunidade. Nem ela será digna de nota se a teoria que ela promove acarreta um rompimento radical e total com a prática indutiva herdada. Neste caso, o cientista corre mesmo o risco de ser alijado da comunidade científica e se ver destituído de sua autoridade epistêmica. O mesmo acontece com aqueles poucos que resistem mudar para o novo paradigma que se mostrou vitorioso. A autoridade prima facie concedida a uma escolha científica decai com o tempo se ela não conquista aliados ou se ela perde aqueles que tinha. Como assinala Kuhn, não houve um momento na resistência de Priestley em que ele se tornou ilógico, mas houve um momento em que ele deixou de ser um cientista, um especialista digno de crédito (Kuhn 2012, p.158).

Se concedemos que a escolha científica individual no contexto de debate entre paradigmas rivais tem autoridade epistêmica prima facie, na medida em que estas escolhas são opostas entre si e partem de pares de igual autoridade intelectual, elas não

Principia 17(3): 439-458 (2013). 
deveriam se anular mutuamente? Não. Como coloca Kuhn, um campo de investigação não progride por ser ciência, mas é ciência porque progride (Kuhn 2012, p.161). A assimetria entre disciplinas maduras e não maduras no que diz respeito ao progresso é aqui sintomática. Na qualidade de herdeiros de uma ciência já constituída e, portanto, reconhecidamente eficiente na resolução de problemas, os membros da comunidade científica projetarão progresso no campo de investigação, mesmo nos períodos de crise. Enquanto persistir a projeção de progresso, as escolhas individuais autônomas terão autoridade e credibilidade. Claro que a persistência muito prolongada da crise pode ameaçar a convicção de que o progresso está ao alcance. E se isto ocorrer, o campo de investigação pode deixar de ser ciência e voltar ao estágio pré-paradigmático. Remetidos de volta à filosofia, diante da discórdia entre pares intelectuais e sem muita esperança de progresso, estes ex-cientistas terão talvez de flertar mais intimamente com a suspensão do juízo. Mas é raro que uma ciência madura tenha este funesto destino.

O resultado do debate entre paradigmas rivais é ainda visto e deve ser visto como progresso porque ele se baseia no acordo não de quaisquer indivíduos, mas de especialistas, indivíduos com autoridade epistêmica. Kuhn coloca este ponto muito claramente na seção XIII:

Se autoridade apenas e particularmente se autoridade não-profissional fosse o árbitro dos debates entre paradigmas, o resultado destes debates seriam ainda revolução, mas não seria revolução científica. A própria existência da ciência depende de se atribuir a competência de escolher entre paradigmas aos membros de um tipo especial de comunidade. Quão especial esta comunidade deve ser para a ciência sobreviver e crescer pode ser indicado pela tenacidade da humanidade de manter o empreendimento científico. (2012, p.166-67)

Vemos assim que a chave para entender o progresso entre paradigmas é o reconhecimento da autoridade epistêmica dos membros de uma comunidade científica e a consequente autonomia epistêmica destes especialistas em relação aos cânones indutivos herdadas no período de debate entre teorias rivais. Essa autonomia lança luz sobre a racionalidade dos julgamentos individuais variados quanto a qual paradigma será mais promissor na resolução de problemas. O especialista também tem uma temporária autonomia em relação aos julgamentos individuais dos demais membros da comunidade. Com o passar do tempo, ela decai se não conquista aliados, e o isolamento pode comprometer a sua autoridade. Temos progresso quando o debate chega a um desfecho por acordo majoritário. O progresso não se deve meramente ao acordo, mas ao acordo entre autoridades epistêmicas. E "que critério melhor poderia haver além da decisão do grupo científico?” (2012, p.169). Na ausência de qualquer prova da objetividade dos cânones indutivos externa à própria prática indutiva, não há critério melhor. A última citação de Kuhn só pode ser lida como uma aceno para 
o relativismo cultural se ignoramos completamente o papel normativo da existência de especialistas e da autoridade epistêmica que lhes deve ser creditada.

A solução aqui proposta para a racionalidade epistêmica do processo de transição entre paradigmas dissocia progresso de sucesso, ela não é demasiada interna, pautada exclusivamente na decisão coletivamente acordada dos especialistas? Certamente que não. Lembremos que no estágio mais avançado da disputa, o paradigma novo já conta com vários sucessos explicativos no seu histórico, tanto quanto o velho. Seria falso, portanto, dizer da solução aqui proposta que ela está comprometida em sustentar que a comunidade científica pode estabelecer acordo sobre o que quer que seja e que aquilo com que concordarem será tomado como verdadeiro. O que está em disputa é apenas a projeção de sucesso futuro, o juízo comparativo sobre qual paradigma será mais bem sucedido na resolução de problemas. E como os próprios cânones indutivos são afetados pelo paradigma, a única fonte extra de autoridade epistêmica para o desfecho deste debate em particular, quando ele ocorrer, é aquela creditada aos especialistas e membros da comunidade científica. Como qualquer indução, a projeção de que o paradigma vencedor será bem sucedido na resolução de problemas pode se mostrar falha. Não há garantias, mas também não se pode dizer que a comunidade científica não fez o melhor que ela poderia realmente ter feito.

\section{Apoio}

Este trabalho foi realizado com o apoio do CNPq.

\section{Referências}

Goodman, N. 1983a. Fact, Fiction and Forecast. Havard University Press.

- 1983b. Ways of Worldmaking. Hackett Publishing Company.

Hoyningen-Huene, P.; Sankey, H. 2001. Introduction. In: P. Hoyningen-Huene; H. Sankey (eds.) Incommensurability and related matters. Kluwer Academic Publishers, p.vii-xxxiv.

Kuhn, T. 1970. Reflexões sobre os meus críticos. In: A. Musgrave; I. Lakaktos (org.) A Crítica e o desenvolvimento do conhecimento. Cambridge University Press, p.285-343.

- 2011 [1973]. Objetividade, juízo de valor e escolha de teorias. In T. Kuhn: A tensão essencial. São Paulo: Editora Unesp, p.339-60.

—. 2011 [1974]. Reconsiderações acerca dos paradigmas. In T. Kuhn: A tensão Essencial. São Paulo: Editora Unesp, p.311-38.

— 2011 [1982]. Comensurabilidade, comparabilidade e comunicabilidade. In T. Kuhn: O caminho desde a Estrutura. São Paulo: Editora Unesp, p.47-76.

- 2003 [1983]. Racionalidade e escolha de teorias. In T. Kuhn: O caminho desde a Estrutura. São Paulo: Editora Unesp, p.255-64.

- 2012. The Structure of Scientific Revolutions, 50 Anniversary Edition. University of Chicago Press.

Principia 17(3): 439-458 (2013). 
Lenz, J. 1974. Problems for the practicalist's justification of induction. In: R. Swinbrune, The Justification of Induction. Oxford University Press.

Putnam, H. 1992. Razão, Verdade e História. Publicações Dom Quixote.

- 2004. The Collapse of the Fact/Value Dichotomy and Other Essays. Harvard University Press.

Reichenbach, H. 1938. Experience and Prediction. The University of Chicago Press.

Salmon, W. 1974. On pragmatic justification of induction. In: R. Swinburne, The Justification of Induction. Oxford University Press.

Scheffler, I. 1982. Science and subjectivity. Hackett Publishing Company.

Shapere, D. 1964. The Structure of Scientific Revolutions. The Philosophical Review 73(3): 383-94.

Siegel, H. 1980. Justification, discovery and the naturalizing of epistemology. Philosophy of Science 47(2): 297-321.

Eros Moreira de Carvalho

UFRGS - Campus do Vale

Instituto de Filosofia e Ciências Humanas

Av. Bento Gonçalves, 9500 - Prédio 43311, Bloco AI, Sala 110

91501-970 - Porto Alegre, RS

BRASIL

eros. carvalho@ufrgs.br

Resumo. Neste artigo, procuro articular e clarificar o papel da autoridade epistêmica de especialistas na explicação de Kuhn para o processo de transição entre paradigmas rivais nos períodos de revolução científica. Se a ciência progride, este processo deveria contribuir para a realização do fim cognitivo da ciência, a saber, a articulação de paradigmas cada vez mais bem sucedidos na resolução de problemas. Mas é difícil ver este processo como sendo racional e realizando o objetivo cognitivo da ciência sem a consideração da autoridade epistêmica. O erro de Kuhn foi enfatizar e clarificar insuficientemente o papel da autoridade epistêmica dos especialistas; seus críticos falharam por ignorá-lo por completo.

Palavras-chave: Thomas Kuhn; racionalidade científica; autoridade epistêmica; escolha de teorias; revolução científica.

\section{Notas}

${ }^{1}$ Posteriormente, Kuhn reserva o termo "paradigma" para exemplares, e passa a utilizar "matriz disciplinar" para a acepção mais ampla do termo original, englobando generalizações simbólicas, modelos, valores cognitivos e os próprios exemplares (Kuhn, 1974). Neste artigo, como estarei trabalhando sobretudo com The Structure of Scientific Revolutions (doravante, $S S R$ ), manterei um uso de "paradigma" na sua acepção mais ampla e mesmo "teoria" será utilizada como um sinônimo.

${ }^{2}$ As traduções neste artigo do texto de Kuhn são de minha responsabilidade.

Principia 17(3): 439-458 (2013). 
${ }^{3}$ Kuhn explicitamente menciona os aspectos teórico, perceptivo e metodológico da incomensurabilidade na seção XII de SSR. Os dois primeiros estão mais intimamente relacionados, já que o fenômeno da variação de significado atinge não só os termos para entidades teóricas, mas também os termos observacionais de uma teoria. Em função disso, Paul Hoyningen-Huene e Harold Sankey sugeriram que a discussão de Kuhn em torno da incomensurabilidade gravita em torno de dois tipos distintos de incomensurabilidade, a semântica e a metodológica. A primeira é a tese de que "teorias científicas alternativas podem ser incomensuráveis em virtude da variação semântica de termos empregados pelas teorias" (Hoyningen-Huene; Sankey 2001, p.ix). A segunda é a tese de que teorias científicas alternativas podem ser incomensuráveis em virtude da ausência de padrões comuns de avaliação teórica" (2001, p.ix).

${ }^{4}$ Kuhn, em trabalhos mais tardios, explicitamente distingue a incomensurabilidade global da local e se defende dos críticos afirmando que jamais sustentou a incomensurabilidade global. No que diz respeito à incomensurabilidade semântica, a sua versão local seria a tese de que a maioria dos termos de uma teoria preserva o seu significado na transição entre paradigmas (Kuhn 1982, p.50-1). De modo semelhante, a incomensurabilidade metodológica, na sua versão local, seria a tese de que alguns padrões de avaliação e valores cognitivos são preservados na transição entre paradigmas.

${ }^{5}$ A vindicação pragmática defendida por Reichenbach (1938) e, posteriormente, por Salmon (1974) é uma prova externa da confiabilidade da indução, ainda que seja uma prova condicional: se há regularidades, então se algum método captura estas regularidades, então necessariamente o método indutivo também as captura no longo prazo. Mais precisamente, se a probabilidade de Gs em relação a Fs é objetiva e definida, digamos, $r$, então se algum método captura esta probabilidade, então necessariamente o limite da frequência relativa de Gs em relação a Fs quando Fs tende ao infinito converge para $r$. O método indutivo é assim uma condição necessária, embora não suficiente, para o sucesso de qualquer método que capture regularidades. A principal dificuldade desta estratégia é que ela permanece silenciosa sobre quando, ao percorrer uma série finita de Fs, podemos destacar a frequência relativa de Gs em relação a Fs como sendo aproximadamente a probabilidade objetiva de Gs em relação a Fs. Mas justamente este destacamento faz parte da prática indutiva corrente (Lenz 1974).

Principia 17(3): 439-458 (2013). 